\title{
Analysis of Positioning Adjustment Approaches for Cutting Inserts of Thread Cutters
}

\author{
Vladimir Grechishnikov ${ }^{1}$, Alexander Isaev ${ }^{1}$, Mikhail Kozochkin ${ }^{1}$, Pyae Phyo Aung ${ }^{1}$ \\ ${ }^{1}$ Moscow State University of Technology “STANKIN”, RU-127055, Moscow, Russia
}

\begin{abstract}
The inclination angle of cutting inserts of thread cutters should be adjustable to provide the required geometry when machining threads. In serial production, this adjustment is realized by changing the carbide shims. In the present paper, the analysis of relationships between geometric parameters and positioning accuracy errors for thread cutters with inserts is presented.
\end{abstract}

\section{Introduction}

In Russian standard GOST 24705-81 "Metric thread. Main dimensions" the application of the threads with different pitches is described and regulated. This allows to take into account the purpose and requirements of the thread when designing new products, but increases the range of threading tools due to a change in the thread helix angle. Using the universal cutters with the cutting edge inclination angle $\lambda=0^{\circ}$ with a variety of the thread helix angles $\tau \neq 0$ does not guarantee optimal cutting conditions and significantly degrades the quality of production.

\section{Methods and Results}

To reduce the product range and to create optimal cutting conditions for machining threads using lathe turning machines, various designs of cutters were created with the ability to tilt the cutting element at the thread helix angle related to the workpiece axis along the pitch diameter in order to optimize the geometric parameters of the cutter [1-3]. This is confirmed by the diagram shown in Fig. 1, which shows two options for the position of the cutting insert. In Fig. 1a the thread helix angle is $\tau>0$ and the cutting-edge inclination angle $\lambda=0^{\circ}$, i.e. the cutting angles on the right and left edges of the cutting part are different. In Fig. 1b, due to the basing shim with the angle $\tau=\lambda$, the cutting conditions for the cutting edges become symmetric.

The values of the clearance angles at the side cutting edges (Fig. 1a) at the angle of inclination of the cutting element $\lambda=0^{\circ}$ are determined by the formulas [4-5]:

$$
\begin{aligned}
& \gamma 1=+\tau ; \\
& \gamma 2=-\tau ; \\
& \alpha 1=\alpha s t-\tau ; \\
& \alpha 2=\alpha s t+\tau ;
\end{aligned}
$$

$$
\operatorname{tg} \tau=\mathrm{p} /(\pi \mathrm{dc}),
$$

where $\gamma_{1}, \gamma_{2}$ are the rake angles on the left and right cutting edge, respectively; $\alpha_{1}, \alpha_{2}$ are the clearance angles on the left and right cutting edge; $\tau$ is the thread helix angle on the pitch diameter; $\alpha_{\mathrm{st}}$ is the clearance angle of cutting edges in static coordinate plane; $\mathrm{P}$ is the thread pitch; $d_{c}$ is the pitch diameter, mm;

For this case, the basing shim is manufactured with the inclination angle $\lambda=0$.

When fitting the rake face of the cutter by $d_{c}$ in the plane normal to the turns of thread (Figure 1, b) at $\lambda_{\text {insert }}=\lambda=\tau$, the angles on the left and right cutting edges are determined by the formulas:

$$
\begin{aligned}
& \gamma 1=\gamma 2=0 ; \\
& \alpha 1=\alpha 2=\alpha s t
\end{aligned}
$$

The cutting conditions become equal for the right and left sides of the cutting edge [6-28].

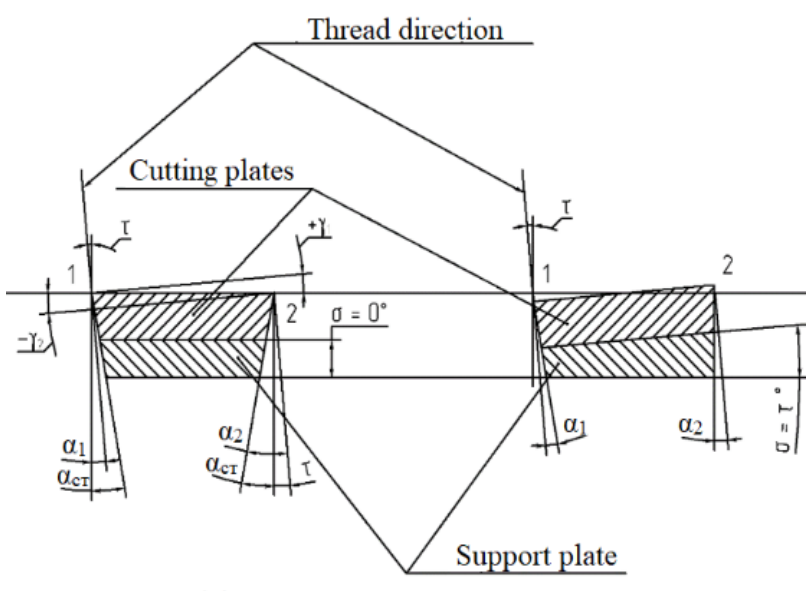

(a)

(b)

Fig. 1. Scheme of fitting the thread inserts: a) $\lambda=\lambda_{\text {insert }}=0^{\circ}$, b) $\lambda=\lambda_{\text {insert }}=\tau$ 
Selection of the dimensions range for basing shims using the values of the angle $\lambda$ is performed by various analytic approaches. For a large dimension range, the number of shims decreases, but it becomes more difficult to choose a suitable angle of the shim. When the dimension range is small, the available quantity of shims increases. Thus, on average, the cutting tools manufacturers have from 7 to 8 shims providing a range of angles from -2.0 to 4.5 degrees.

There are technical solutions for the design of thread cutters with the adjustable angle $\lambda$ which allows to shorten a dimension range for shims.

The thread cutting tool with a rotary holder having the adjustable cutting-edge inclination angle (with $\lambda>0$ ) is shown in Figure 2(Patent 60414).

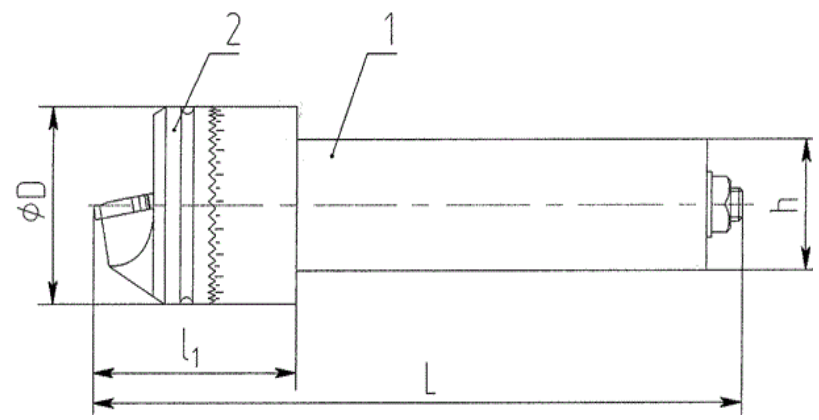

Fig. 2. Illustration of patent No. 60414 (RU): 1 - thread cutter's body; 2 - adjustable head

Threading tool with a rotary tool holder consists of body (1) and holder (2) having a carbide insert fastened with a screw. On the left end of the cutter body, the serrations are made, which in contact with the holder fix a position of the thread insert relative to the cut thread taking into account the change in the angle $\tau$.

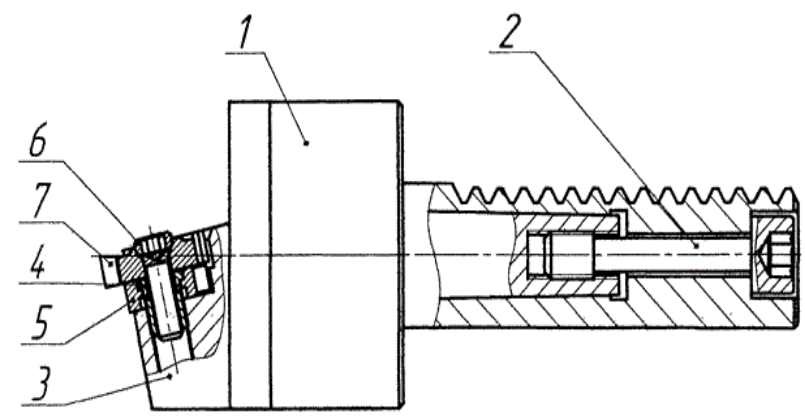

Fig. 3. Illustration of patent No. 60414 (RU): 1 - body; 2 clamping screw; 3 - rotary holder; 4 - fixing spring of shim; 5 shim; 6 - fixing screw; 7 - cutting insert

Another variant of the thread cutting tool with a rotary tool holder consists of body (1), scale holder (2), cutting replaceable insert (3), fixed screw (4) and basing shim (5). The body has a form of a stepped cylinder with a flattened surface and corrugations on it in the tail part and a vernier scale in the head part. The axis of rotation of the holder intersects the axis of the machine spindle and coincides with the symmetry axis of the cutting-edge tip. This axis is located in a plane passing through the cutter's tip parallel to the main plane. The basing shim is located between the cutting insert and the holder.
These designs are not widely used due to the complexity of their manufacture and large overall dimensions. And, as a consequence, the base shims remain the main option for adjusting the angle $\lambda$.

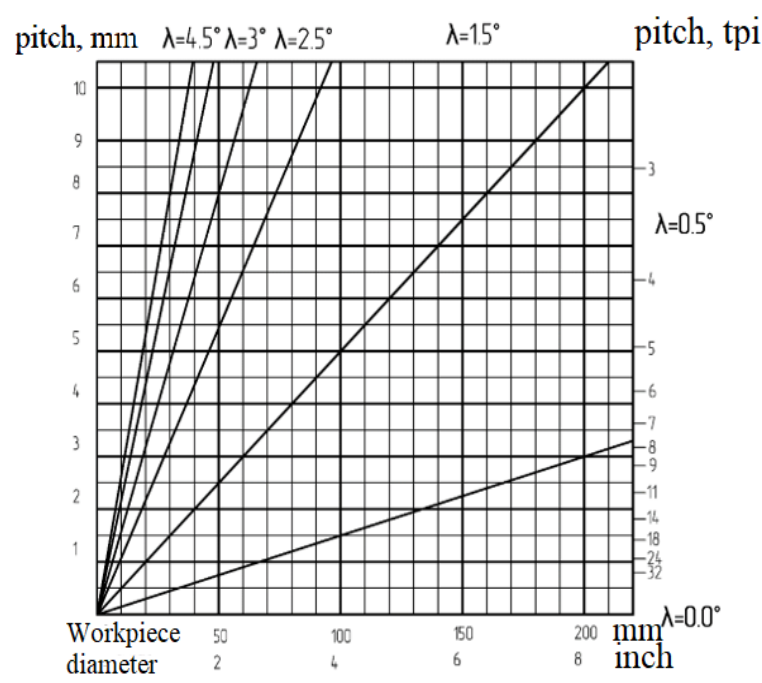

Fig. 4. Diagram of the selection of basing shims from the Vargus catalog

In the today's market of metalworking tools, there are two solutions for the choice of the dimension range of the basing shims. Different cutting edge inclination angles $\lambda$ allow providing different cutting conditions on the side cutting edges and reduce the number of carbide shims, the cost of which is comparable with the cost of the cutting insert.

The selection diagram for the shims is shown in Figure 4 (for products by Vargus) and Figure 5 (for products by Sandvik Coromant). According to the selection diagram and depending on the diameter of the workpiece and the thread pitch, one can determine the required basing shim. Table 1 summarizes both solutions in a form convenient for analysis.

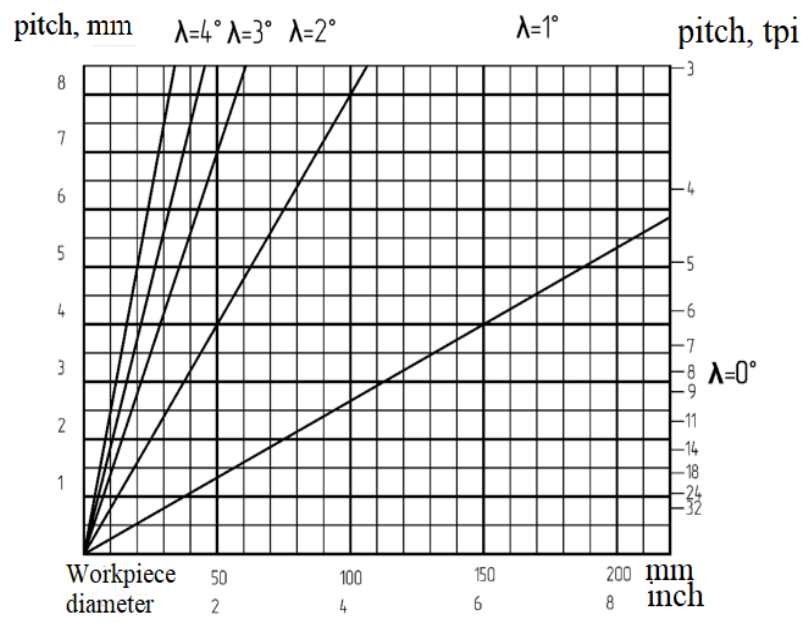

Fig. 5. Diagram of the selection of basing shims from the Sandvik Coromant catalog 
Table 1. Recommendations by manufacturers of cutting tools for choosing the interval of dimensions

\begin{tabular}{|c|c|c|c|c|c|}
\hline \multirow{2}{*}{$\begin{array}{c}\text { Cutting edge } \\
\text { inclination } \\
\text { angle } \lambda \\
\text { (Vargus) }\end{array}$} & \multicolumn{2}{|c|}{$\begin{array}{c}\text { Thread helix } \\
\text { angle } \tau\end{array}$} & $\begin{array}{c}\text { Cutting } \\
\text { edge } \\
\text { inclination } \\
\text { angle } \lambda \\
\text { (Sandvik } \\
\text { Coromant) }\end{array}$ & \multicolumn{2}{|c|}{$\begin{array}{c}\text { Thread helix } \\
\text { angle } \tau\end{array}$} \\
& min & $\max$ & $\min$ & $\max$ \\
\hline$-1,50$ & $-2,00$ & $-1,00$ & $-2,00$ & $-2,50$ & $-1,50$ \\
\hline$-0,50$ & $-1,00$ & $-0,25$ & $-1,00$ & $-1,50$ & 0,50 \\
\hline 0,00 & $-0,25$ & 0,25 & 0,00 & $-0,50$ & 0,50 \\
\hline 0,50 & 0,25 & 1,00 & 1,00 & 0,50 & 1,50 \\
\hline 1,50 & 1,00 & 2,00 & 2,00 & 1,50 & 2,50 \\
\hline 2,50 & 2,00 & 3,00 & 3,00 & 2,50 & 3,50 \\
\hline 3,50 & 3,00 & 4,00 & 4,00 & 3,50 & 4,50 \\
\hline
\end{tabular}

For convenience and comparison of options, tabular values are represented in the form of graphs (Figure 6 and 7). The charts show the difference in recommendations of the cutting tools producers.

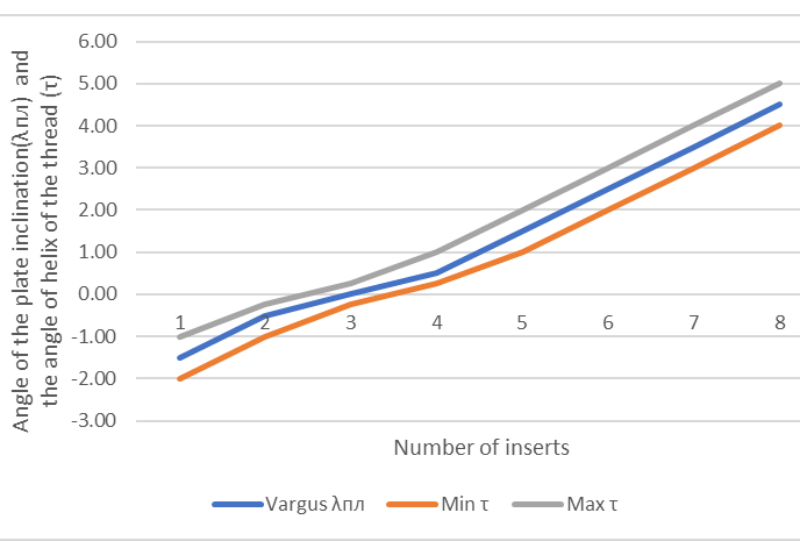

Fig. 6. Graphs for selection of $\lambda$ angle by Vargus

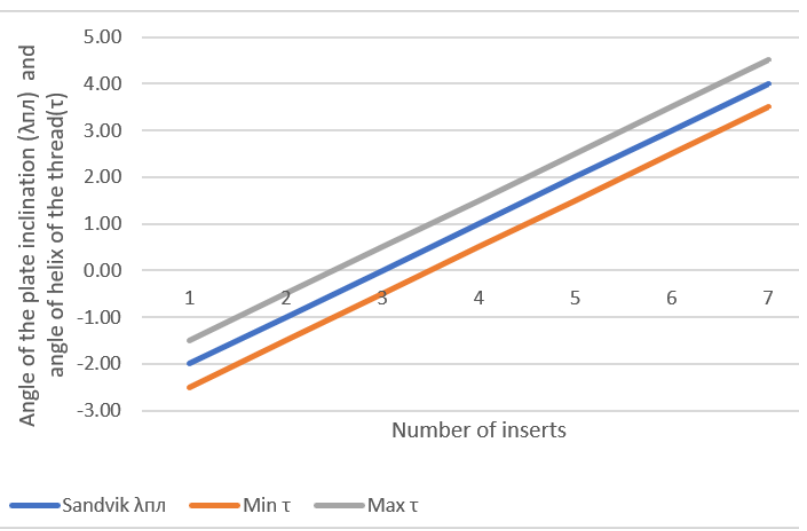

Fig. 7. Graphs for selection of $\lambda$ angle by Sandvik Coromant

To evaluate the positioning accuracy of the basing shims, GOST 24705-81 was used. This standard has a fairly wide range of threads with different diameters and pitches. Figure 8 shows a diagram of the values of the thread helix angles depending on the diameter and pitch.

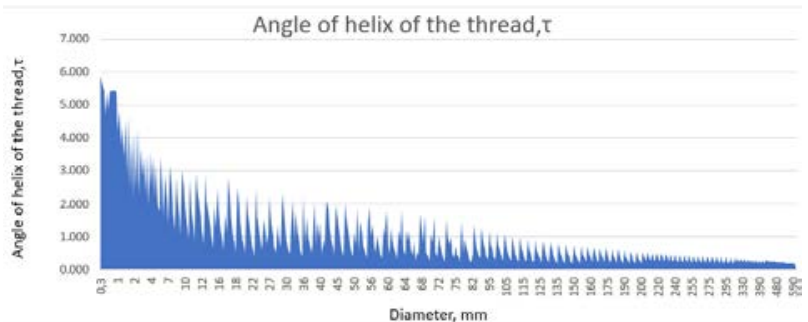

Fig. 8. Diagram of the thread helix angles depending on the diameter and pitch according to GOST 24705-81.

After combining the graph of the choice of $\lambda$ and the sorted diagram of the thread helix angles $\tau$, it can be concluded that the basing shims by Vargus are closer to the calculated values of the thread helix angles the thread on the $d_{c}$ (Figure 9).

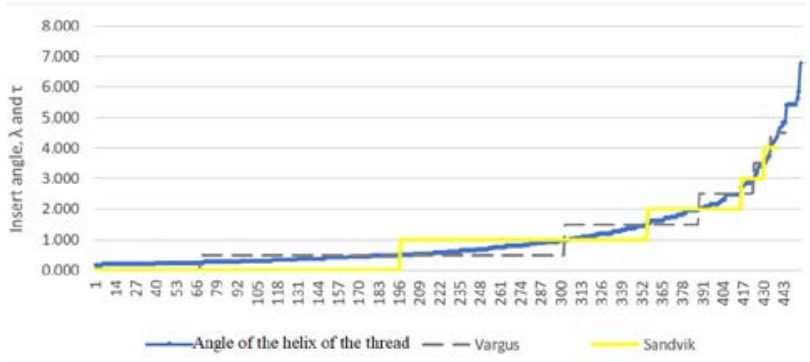

Fig. 9. Change of the thread helix angles and the choice of angle $\tau$ according to GOST 24705-81 and the choice of $\lambda$ according to the manufacturers of the basing shims

\section{Conclusions}

The basing shims by Vargus are more preferable for machining threads according to GOST 24705-81 compared to Sandvik Coromant shims as they provide optimal cutting angles for the right and left cutting edges.

Increasing the range of basing shims reduces the installation errors of cutting inserts calculated using the values of the thread helix angle $\tau$.

\section{Acknowledgments}

This research was funded by Ministry of Science and Higher Education of the Russian Federation, Grant No. 0707-2020-0031. This work was carried out using equipment provided by the Center of Collective Use of MSUT "STANKIN".

\section{References}

1. V.A. Grechishnikov, Y.E. Petukhov, V.B. Romanov, A.V. Isaev, P.V. Domnin, P.M. Pivkin, Rus. Eng. Res., 38, 1018-1021 (2018)

2. V.A. Grechisnikov, Rus. Eng. Res. 40, 51-54 (2020) 
3. V.A. Grechishnikov, Y.E. Petukhov, P.M. Pivkin, A.A. Timofeev, A.V. Isaev, V.B. Romanov, I.V. Minin, L.E. Shvartsburg, S.V. Yurasov, Rus. Eng. Res., 40, 768-771 (2020)

4. S.N. Grigoriev, G.M. Martinov, Procedia CIRP, 1(1), 238 (2012)

5. V.A. Grechishnikov, S.N. Grigoriev, P.M. Pivkin, M.A. Volosova, A.V. Isaev, D.V. Nikitin, I.V. Minin, EPJ Web of Conferences, 224, 05001 (2019)

6. V.V. Kuzin, S.N. Grigoriev, M.A. Volosova, Refract. Ind. Ceram., 54, 376, (2014)

7. V.V. Kuzin, S.N. Grigoriev, M.A. Volosova, J. Frict. Wear, 36(1), 40, (2015)

8. V.A. Grechishnikov, Y.E. Petukhov, P.M. Pivkin, A.V. Isaev, S.V. Bushuev, V.B. Romanov, Meas. Tech., 58, 848-853 (2015)

9. A.V. Gusarov, S.N. Grigoriev, M.A. Volosova, Y.A. Melnik, A. Laskin, D.V. Kotoban, A.A. Okunkova, J. Mater. Process. Technol., 261, 213 (2018)

10. A.S. Metel, V.P. Bolbukov, M.A. Volosova, S.N. Grigoriev, Y.A. Melnik, Instrum. Exp. Tech., 57(3), 345, (2014)

11. R.S. Khmyrov, S.N. Grigoriev, A.A. Okunkova, A.V. Gusarov, Phys. Procedia, 56, 345 (2014)

12. X. Kong, Z. Ding, L. Xu, L. Zhu, J. Zhang, C. Wu, A. Isaev, EPJ Web of Conferences, 224, 05009 (2019)

13. A.V. Isaev, V.A. Grechishnikov. Rus. Eng. Res., 30, 413-417 (2010)

14. S.N. Grigoriev, D.A. Masterenko, V.I. Teleshevskii, P.N. Emelyanov, Meas. Tech, 55(11), 1311 (2013)

15. A.V. Isaev, M.P. Kozochkin, Meas. Techniq., 56, 1155-1161 (2014)

16. M.A. Volosova, S.N. Grigoriev, A.S. Metel, A.A. Shein, Coatings, 8, 287, (2018)

17. R.M. Khusainov, R.M. Khisamutdinov, S.Y. Yurasov, S.A. Belov, O.V. Goryacheva, V.A. Grechishnikov, A.V. Isaev, V.B. Romanov, Rus. Eng. Res., 37, 344-347 (2017)

18. M.A. Volosova, S.N. Grigoriev, V.V. Kuzin, Refract. Ind .Ceram., 56, 197, (2015)

19. S.N. Grigoriev, V.A. Grechishnikov, M.A. Volosova, X. Jiang, P.M. Pivkin, IOP Conference Series: Materials Science and Engineering, 971, 022065 (2020)

20. S.N. Grigoriev, M.P. Kozochkin, P.M. Pivkin, 2020 International Multi-Conference on Industrial Engineering and Modern Technologies (FarEastCon) (2020)

21. P.M. Pivkin, A.A. Ershov, A.B. Nadykto, 2020 International Multi-Conference on Industrial Engineering and Modern Technologies (2020)

22. P.M. Pivkin, V.A. Grechishnikov, A.A. Ershov, A.B. Nadykto, Emerging Imaging and Sensing Technologies for Security and Defence V; and
Advanced Manufacturing Technologies for Microand Nanosystems in Security and Defence III, 11540, 1154014 (2020)

23. S.N. Grigoriev, P.M. Pivkin, V.A. Grechishnikov, Y.E. Petukhov, M.A. Volosova, A.B. Nadykto, Emerging Imaging and Sensing Technologies for Security and Defence V; and Advanced Manufacturing Technologies for Micro-and Nanosystems in Security and Defence III, 11540, 115401E (2020)

24. P.M. Pivkin, A.B. Nadykto, V.A. Grechishnikov, M.A. Volosova, I.V. Minin, S.N. Grigoriev, Emerging Imaging and Sensing Technologies for Security and Defence V; and Advanced Manufacturing Technologies for Micro-and Nanosystems in Security and Defence III, 11540, $115401 \mathrm{G}$ (2020)

25. S.N. Grigoriev, M.A. Volosova, A.A. Okunkova, S.V. Fedorov, K. Hamdy, P.A. Podrabinnik, P.M. Pivkin, M.P. Kozochkin, A.N. Porvatov, Technol., 8(3), 49 (2020)

26. S.N. Grigoriev, M.A. Volosova, A.A. Okunkova, S.V. Fedorov, K. Hamdy, P.A. Podrabinnik, P.M. Pivkin, M.P. Kozochkin, A.N. Porvatov, J. Manuf. Mater. Process., 4(3), 96 (2020)

27. S.N. Grigoriev, M.A. Volosova, V.A. Grechishnikov, P.M. Pivkin, P.Y. Peretyagin, A.A. Zelensky, Procedia CIRP, 95, 337-342 (2020)

28. A.V. Isaev, R.R. Khamzin, I.V. Minin, P.M. Pivkin, M. Leonesio, MATEC Web of Conferences, 329, 03073 (2020) 